http://jmscr.igmpublication.org/home/

ISSN (e)-2347-176x ISSN (p) 2455-0450

crossref DOI: https://dx.doi.org/10.18535/jmscr/v7i12.124

Journal Of Medical Science And Clinical Research

\title{
Functional results of primary hemiarthroplasty in four part fractures and fracture dislocations of proximal humerus: A prospective study
}

\author{
Authors
}

\author{
Munir Farooq ${ }^{1}$, Ajaz Ahmad Bhat ${ }^{2}$, Zubair Ringshawl $^{3}$ \\ ${ }^{1}$ Professor and Head of Orthopaedic Department, GMC Srinagar \\ ${ }^{2}$ Medical Officer, Department of Health, J\&K \\ ${ }^{3}$ Postgraduate Scholar, Orthopaedic Department, GMC Srinagar
}

\begin{abstract}
Purpose. To evaluate early functional outcomes of primary hemiarthroplasty for 4-part proximal humeral fractures with or without dislocation.

Patients and Methods: This prospective study was conducted on 20 patients in the Department of Orthopaedics, GMC, Srinagar. 15 men and 5 women aged 40 to 72 (mean, 55.4) years underwent hemiarthroplasty from August 2016 to August 2018, for 4-part proximal humeral fractures with or without dislocation. All the patients reported normal shoulder function prior to injury. The range of shoulder motion and muscle power were evaluated, as were subjective pain and satisfaction (using the UCLA scoring system).

Results: At the final follow-up, the mean maximum abduction was $139.5^{\circ}$ and the mean maximum forward flexion was $145.6^{\circ}$. All patients had radiographic union of the tuberosities except two (one had resorption of GT and one had proximal migration of GT, both had poor results). The mean UCLA score was 28; 14 patients attained good-to-excellent scores, whereas 6 attained lower (fair-to-poor) scores. The mean UCLA score was higher in patients aged $<60(n=13)$ than those who were older (n=7) [30 vs 24, $p=0.07]$. Majority of the patients had complete relief of pain and were satisfied with the procedure.

Keywords: Hemiarthroplasty, Proximal humerus Fractures, Primary, Shoulder, Trauma.
\end{abstract}

\section{Introduction}

The proximal humerus is involved in nearly $5 \%$ of all fractures ${ }^{1}$. They occur most commonly in elderly population. The incidence of these fractures has increased considerably in the last two decades, probably due to increase in the life expectancy and the associated increase in the incidence of osteoporosis ${ }^{2}$. In patients older than 65 years, about $60 \%$ of all proximal humerus fractures happen due to indoor (low energy) trauma ${ }^{3}$. In younger patients, high energy trauma is the cause and displacement is often more severe. These patients usually have a fracture dislocation ${ }^{4}$.

Majority of the proximal humerus fractures are minimally displaced and can be treated non-operatively with good functional results ${ }^{5}$. However unstable displaced fractures often require surgical treatment to avoid painful and dysfunctional malunion ${ }^{6}$.

Treatment of these unstable, displaced and comminuted fractures remains a challenge and optimal treatment continues to be controversial. Many different techniques of 
internal fixation have been described including bone sutures, tension band, cerclage wires, krischner (K) wires, T-plates, intramedullary devices, double tubular plates, semitubular blade plate, the Plant Tan Humerus Fixator plate and the Polaris nail ${ }^{7}$. Various complications have been reported using these techniques including cut-out or back out of the screws and plates, avascular necrosis, non-union, mal-union, nail migration, rotator cuff impairment and impingement syndrome ${ }^{8,9}$. This results in a painful shoulder with poor function ${ }^{10}$. Secondary prosthetic replacement of the humeral head in these fractures has also yielded unsatisfactory functional results ${ }^{11}$.

To overcome the common problems associated with the treatment of these fractures, the AO/ASIF group developed the proximal humeral internal locking system (PHILOS) plate. It aims to preserve the biology of humeral head by minimizing soft tissue dissection and secure an anatomical reduction using multiple screws with angular stability, thereby Improving stability in osteoporotic bone $^{12}$. But it also reportedly caused Avascular necrosis ${ }^{13}$ tuberosity avulsion, nonunion and secondary stiffness.

Severely displaced fractures of the proximal part of the humerus have not achieved consistently acceptable results when treated with conservative methods or open reduction and internal fixation techniques 13,14 . Hemiarthroplasty as a primary treatment alternative has been proposed in most relevant studies; however in some reports poor results were obtained ${ }^{15}$. Hemiarthroplasty is suggested as a treatment option in three and four part fractures with osteoporotic bone with a compression fracture affecting more than $45 \%$ of the head, and split fractures when the separated part is greater than $45 \%$ of the humeral head ${ }^{16}$.

\section{Patients and Methods}

Between August 2016 and August 2018, 15 men and 5 women aged 40 to 72 (mean, 55.4) years underwent hemiarthroplasty for comminuted 4part proximal humeral fractures with or without dislocation that were non-amenable by internal fixation. 14 of the patients injured the right side. All patients reported normal shoulder function prior to injury. True AP, Scapular V-Y and Velpeau view was done, also CT Scan with 3D reconstructioin. Patients with associated ipsilateral upper-limb fractures, neurovascular injury, compound fractures, pathological fractures or similar previous injury were excluded.

A modular prosthesis was used in all patients. Its stem was 130-mm long for all patients; 12 received size- 10 or -11 stems, and the remaining 8 received size- 9 and -8 stems. Its humeral head thickness was one size less or equal to the extracted humeral head.

Surgeries were performed by a single surgeon via a delto-pectoral approach. The fractured lesser tuberosity was retracted medially to expose the humeral head. The long head of the biceps tendon was tenotomised at its insertion at the superior glenoid tubercle and then tenodised into the groove for the tendon of the long head of the biceps. Rotator cuff anatomy was visually inspected. Thinning, attenuation, and minor tears of the rotator cuff were encountered in few patients. After thorough medullary lavage, antibiotic impregnated cement was delivered by a cement gun in a retrograde fashion. The prosthesis was inserted, and the tuberosities were placed under tension and repaired with 2-0 Ethibond nonabsorbable sutures. The gap in the rotator cuff between the anterior edge of the supraspinatus and the superior edge of the subscapularis was closed with multiple interrupted non-absorbable sutures.

Postoperatively, a sling pouch was used. Gravity assisted pendulum exercises and passive motion exercises were allowed on day 1. At week 3, assisted forward elevation and supine external rotation and full elbow range-of-motion exercises were allowed for the next 6 weeks or longer (until 
adequate tuberosity healing). At weeks 6 to 8 , stretching and strengthening of the shoulder with the help of a theraband was allowed under supervision. Daily home exercises were then prescribed for 6 to 10 weeks, and activities of daily living (bathing, eating, and personal hygiene) were allowed. Daily home exercises were encouraged for at least 6 month. Patients were followed up at weeks 2 and 6 , months 3 and 6 , and then at 9 months. The range of shoulder motion and muscle power were evaluated, as were subjective pain and satisfaction (using UCLA scoring).

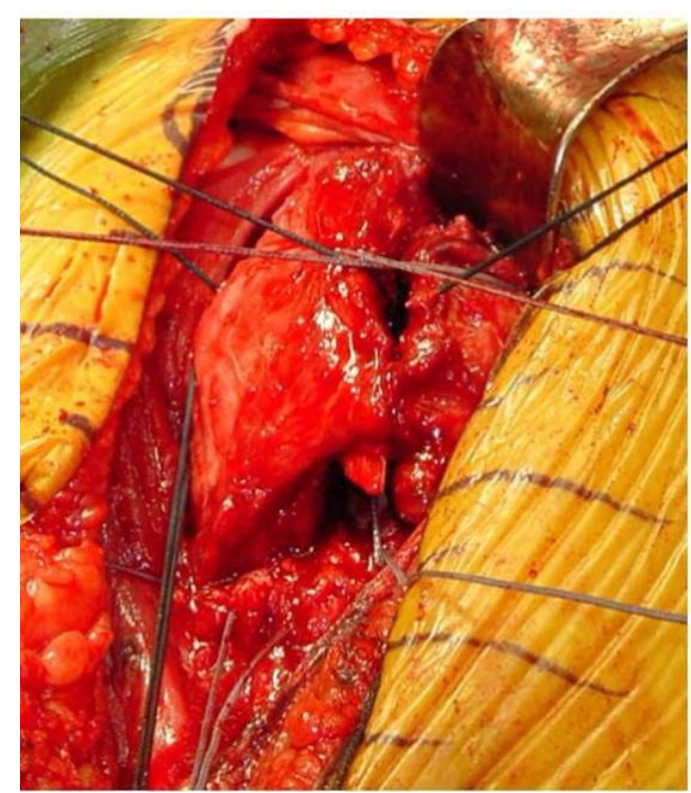

Figure 1(a)

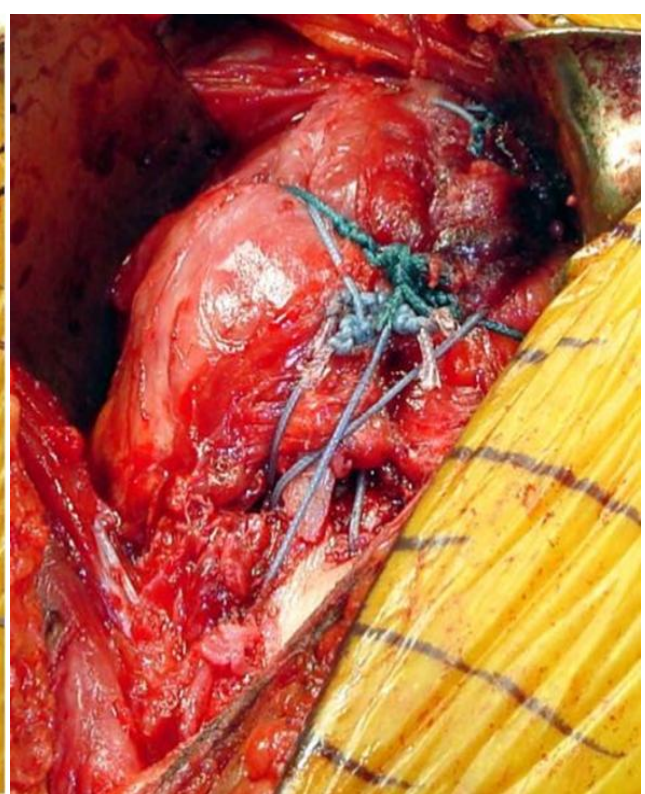

1(b)

Figure 1(a) and 1(b) showing fixation of tuberosities using 2-0 ethibond and placed under tension after fixation of prosthesis

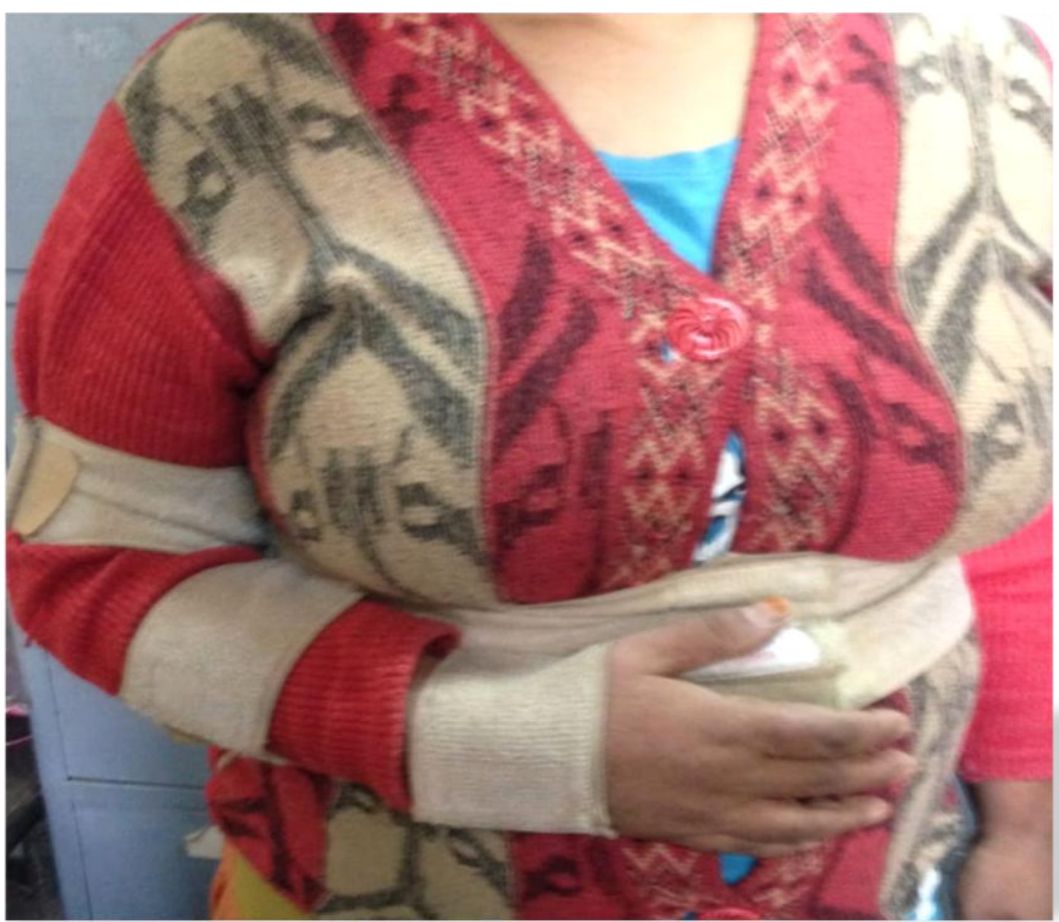

Figure 2: Showing post operative immobilization in 20 to 30 degrees of abduction 


\section{Results}

The results of 20 consecutive patients who underwent primary hemiarthroplasty for four part proximal humeral fracture or fracture dislocation at Department of Orthopaedics, GMC Srinagar August 2016 to August 2018 were evaluated. All patients included in the study were evaluated at a minimum of 9 month follow up after surgery with the help of University of Calfornia at Los Angles Scale (UCLA).

There were 15 male and 5 female patients in the age group of 40 to 72 years. 15 patients had trauma due to fall and 5 had due to road traffic accident (RTA). One patient had associated hip dislocation. Right side which was dominant in all patients was involved in 14 patients. The mean injury-to-surgery interval was 12 (range 7-21) days. Mean operative time was 102 (range, 90120) minutes. The mean time to radiographic union of the tuberosities was 8.3 (range, 6-15) weeks.

At the final follow-up, the mean maximum abduction was $139.5^{\circ}$, and the mean maximum forward flexion was $145.6^{0} .80 \%$ of the patients had no pain at final follow -up. $80 \%$ of the patients were satisfied with the procedure. Muscle strength score was 5 in $60 \%$ of patients and 4 in $30 \%$ of patients as per UCLA muscle strength score (maximum $=5$; minimum $=0$ ).

The mean UCLA score was 28; 14 attained goodto-excellent scores whereas 6 attained lower (fairto-poor) scores. Among those who had fair to poor results, one had Greater tuberosity resorption and one had superior migration of greater tuberosity. Four patients aged above 65years adhered poorly to rehabilitation protocol.

The mean UCLA score was better in patients aged $<60(n=13)$ than those who were older $(n=7)$ [30 vs. $24, \mathrm{P}=0.005$ ].

Complications include superficial wound infection in 2 patients, however it got resolved by oral antibiotics. One patient had GT Resorption and one had superior migration of GT. One patient developed hypertrophic scar, however painless.
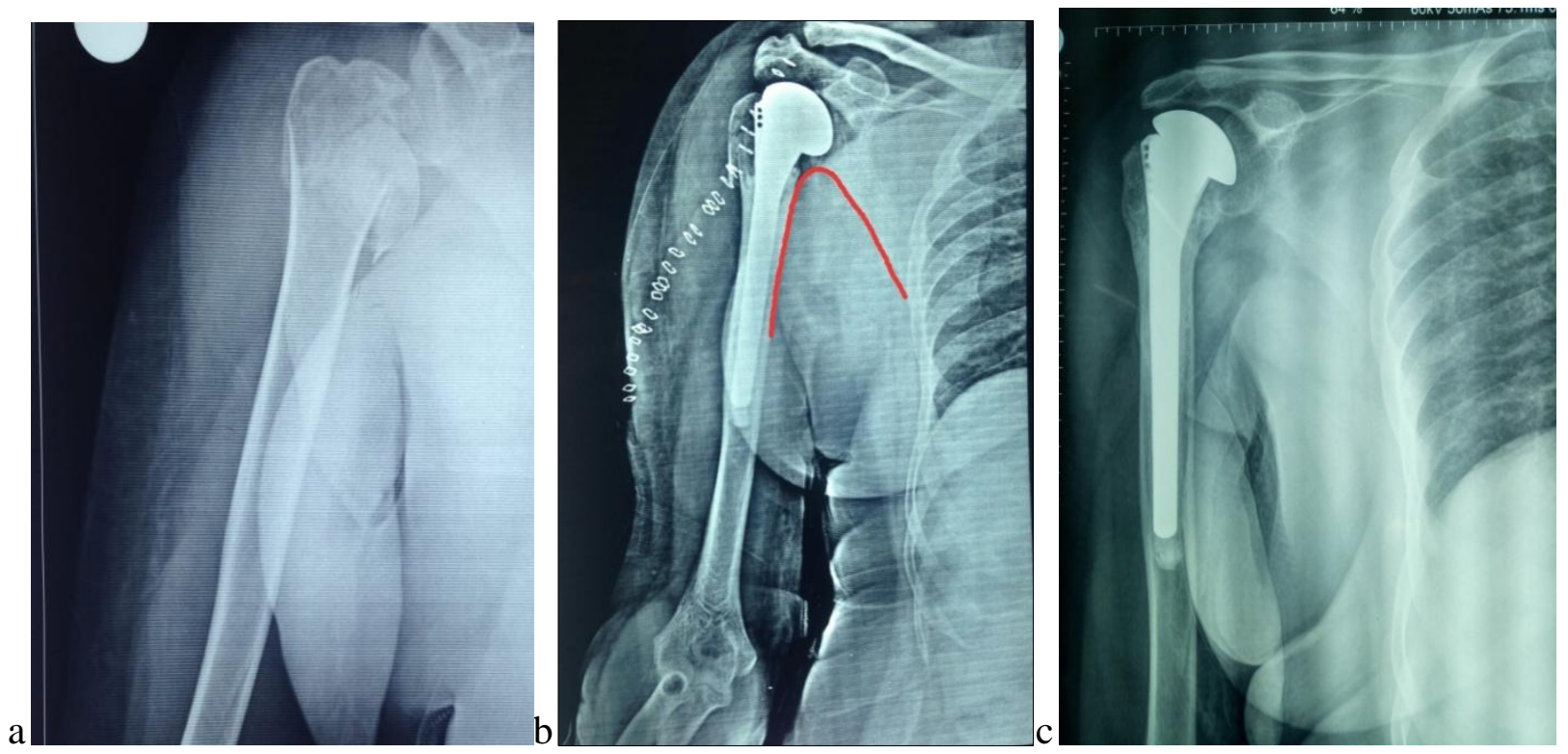

Figure 3 (a) showing 4 part fracture dislocation with head split. (b) A well placed prosthesis, fixation of Greater Tuberosity and Restoration of Gothic Arch( Shenton's line of shoulder). (c) showing union of Greater Tuberosity. 

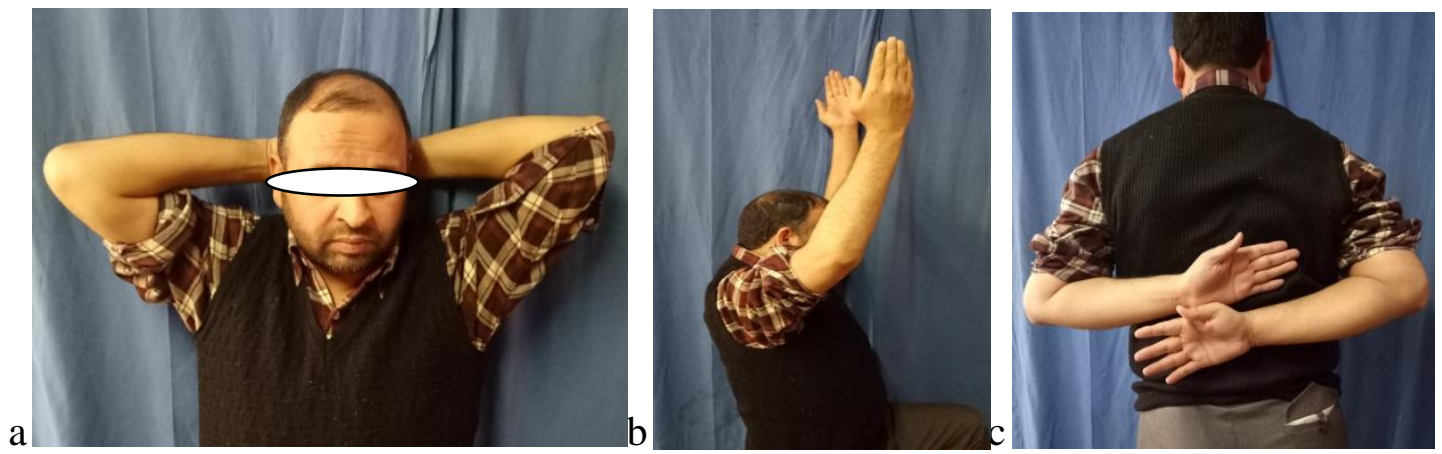

Figure 4 (a),(b) and (c): showing Range of Motion
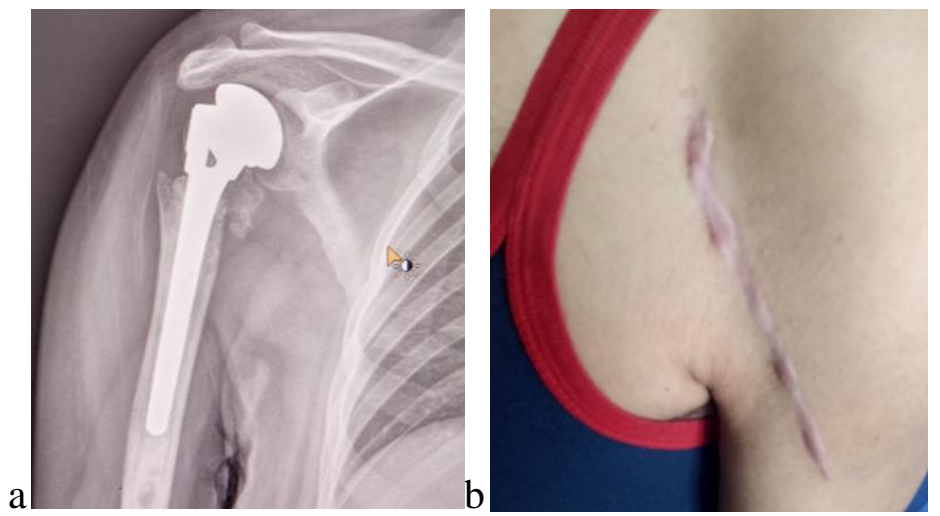

Figure 5 (a) Showing resorption of Greater Tuberosity (b) Showing hypertrophic Scar.

\section{Discussion}

The vast majority of proximal humeral fractures are non displaced or minimally displaced and can be affectively treated by conservative methods.

Severely displaced fractures of the proximal humerus have not achieved consistently acceptable results when treated with conservative methods or open reduction and internal fixation

Conservative methods cannot reproduce the anatomy, risk of avascular necrosis, articular in congruency and high incidence of poor clinical and functional results led many investigators to search for new treatment modalities.

Open reduction and internal fixation using minimal implants (stainless steel wires, screws, heavy sutures) goes into disfavor because of poor reconstruction, loss of fixation, risk of $\mathrm{AVN}$, need for prolonged immobilization and poor clinical and functional results.

In the last few decades, traumatic events especially RTA have increased. Because of the improved health facilities, life expectancy has also increased. Most of the patients want a painless mobile and stable shoulder joint.
Hemiarthroplasty of the shoulder in the management of severely communited fractures of the proximal humerus have the advantage of surgical reconstruction, no risk of $\mathrm{AVN}$, immediate postoperative mobilization and good functional results as documented by many authors $^{17,18,19}$.

Selection of cases for joint replacement is perhaps the single most important factor in achieving good results. Many patients with injury to shoulder region presents late and this affects the outcome. Earlier attempts of reconstruction, shoulders with nerve injury also affects the outcome. Selection of prosthesis is another important factor for the achievement of good clinical and functional results. Hemiarthroplasty is the best treatment modality for comminuted proximal humeral fractures $^{20,21}$. It enables good pain relief, but functional limitation may persist ${ }^{21,22}$. Patient age, gender, injury-to surgery interval, rehabilitation time, implant used, fracture pattern and condition of the rotator cuff affect functional outcome $\mathrm{e}^{23,24,25}$, as does anatomic union of the tuberosities and rotator cuff ${ }^{26-30}$. Better functional outcomes are 
achieved following primary than secondary hemiarthroplaties $^{31-33}$.

Younger patients are more likely to have an intact rotator cuff and/or good bone stock at the tuberosity, leading to healthier abductor function of the arm and better functional outcomes ${ }^{34-38}$.

However, this is a technically demanding procedure. For good results, proper version, height and proper fixation of GT with respective to prosthetic head are keys to success ${ }^{21}$. Union of GT at proper position $(6-12 \mathrm{~mm}$ from superior most part of humeral head) also influences functional outcome.

Limitations of our study included the lack of a control group, the small sample size, and wide age range of the patients. Longer follow-up is needed to comment on implant loosening and wear.

\section{Conclusion}

Proximal humerus fractures are the most common fracture of the shoulder girdle and are a significant health-care burden, especially in the elderly population. It is crucial to perform a full clinical evaluation, including relevant imaging, in order to treat these injuries appropriately. Both patient factors and injury factors should be closely scrutinized in choosing the need for and the type of surgical intervention. Patient factors include age, quality of bone, and the presence of comorbidities, while injury factors include fracture pattern and timing of injury. In more complex and displaced fractures in osteoporotic bone, hemiarthroplasty is most commonly performed. To ensure clinical success in hemiarthroplasty the tuberosities need to be reconstructible and possess the potential to heal. If not, reverse total shoulder arthroplasty should be considered. The likelihood of a successful outcome can be viewed in descending order with a hemiarthroplasty, with reconstructible tuberosities being most likely, followed by reverse total shoulder arthroplasty without reconstructible tuberosities and, finally a hemiarthroplasty without reconstructible tuberosities.

\section{References}

1. Warner JJP, Costouros JC, Gerber C (2006) Fratture dell'epifisi prossimale dell'adulto, vol.2. Cap.31.Rockwood and Green.

2. Kannus p, Palvanen M. Niemi S. Paakkari J, Jarvinen M, Vuori I. osteoporotic fractures of the proximal humerus in elderly finnish persons: sharp increase in 1970-1998 and alarming projections for the new millennium. Acta Orthop Scand 2000; 71: 465-70.

3. Solberg BD, Moon CN, Franco DP, Paiement GD: Locked plating of 3-and 4part proximal humerus fractures in older patients: The effect of initial fracture pattern on outcome. J Orthop Trauma 2009;23(2):113-119.

4. Moonot P, Ashwood N, Hamlet M. Early results for treatment of three and four part fractures of the proximal humerus using the PHILOS plate system. J Bone Joint Surg [Br] 2007;89-B:1206-1209.

5. Koval KJ, Gallagher MA, Marsicano JG, Cuomo F, McShinawy A, Zuckerman JD. Functional outcome after minimally displaced fractures of the proximal part of the humerus. J Bone Joint Surg Am 1997; 79(2): 203-7.

6. Jobin CM, Galatza LM, (2012) Proximal humerus fractures: pin, plate or replace. Semin Arthro 23:74-82.

7. Compito CA, Self EB, Biglani LU. Arthroplasty and acute shoulder trauma. Reasons for success and failure. Clin Orthop 1994 ;307: 27-36.

8. Bastian JD, Hertel R (2009) Osteosynthesis and hemiarthroplasty of fractures of the proximal humerus: outcomes in a consecutive case series. J Should Elb Surg 18:216-219.

9. Gerber C, Schneeberger AG, Vinh TS (1990) The arterial vascularization of the humeral head. An anatomical study. J Bone Joint Surg Am 32:115-121. 
10. Gristina A G, Webb L X, Carter R E. the monospherical total shoulder. Orthop Trans 1985; 9: 54.

11. Zyto K Angus W, Frostick SP, Preston BJ. Outcome after hemiarthroplasty for three and four part fractures of the proximal humerus. J Shoulder Elbow Surg 1998; 7: 85-89.

12. Boileau P, Walch G: the three dimensional geometry of the proximal humerus : implications of surgical technique and prosthetic design, J Bone Joint Surg 1997; 79B:857.

13. Wijgman AJ, Roolker W, Patt TW, Raaymarkers EL, Marti RK. Open reduction and internal fixation of three and four part ftractures of the proximal part of the humerus. J Bone Joint Surg [Am] 2002;84-A:1919-1925.

14. Schlegel TF, Hawkins RJ. Displaced proximal humeral fractures; Evaluation and treatment. J Am Acad Orthop Surg 1994;2:54-66.

15. Robinson CM, Page RS, Hill RM, et al. primary hemiarthroplasty for treatment of proximal humerus fractures. $J$ Bone Joint Surg Am, 2003;85-A.

16. Wijgman AJ, Roolker W, Patt TW, Raaymarkers EL, Marti RK. Open reduction and internal fixation of three and four part ftractures of the proximal part of the humerus. J Bone Joint Surg [Am] 2002;84-A:1919-1925.

17. Robinson CM, Page RS, Hill RM, et al. primary hemiarthroplasty for treatment of proximal humerus fractures. J Bone Joint Surg Am, 2003;85-A.

18. Bankart AS. Recurrent or habitual dislocation of the shoulder joint.Br Med J 1923;2:1132-1133.

19. Howell SM, Galinat BJ. The glenoidlabral socket. A constrained articular surface. Clin Orthop 1989;243:122-125.

20. Neer CS 2nd.Displaced proximal humeral fractures. II. Treatment of three- part and four-part displacement. J Bone Joint Surg Am 1970;52:1090-103.

21. Gronhagen CM, Abbaszadegan H, Revay SA, Adolphson PY. Medium- ter results after primary hemiarthroplasty for comminute proximal humerus fractures: a study of 46 patients followed up for an average of 4.4 years. J Shoulder Elbow Surg 2007;16:766-73.

22. Kontakis G, Koutras C Tosounidis T, Giannoudis P. Early management of proximal humeral fractures with hemiarthroplasty: a systematic review. J Bone Joint Surg Br 2008;90:140713.

23. Bosch U, Skutek M, Fremerey RW, Tscherne H. Outcome after primary and secondary hemiarthroplasty in elderly patients with fractures of the proximal humerus. J Shoulder Elbow Sur 1998; 7:479-84.

24. Boileau P, Krishnan SG, Tinsi L, Walch G, Coste JS, Mole D. Tuberosity malposition and migration: reasons for poor outcomes after hemiarthroplasty for displaced fractures of the proximal humerus. J Shoulder Elbow Surg 2002;11:401-12.

25. Esen E, Dogramaci Y, Gultekin S, Deveci MA, Suluova F, Kanatli U, et al. Factors affecting results of patients with humeral proximal end fractures undergoing primary hemiarthroplasty: a retrospective study in 42 patients. Injury 2009;40:1336-41.

26. Reuther F, Muller S, Wahl D. Management of humeral head fractures with a trauma shoulder prosthesis: correlation between joint function and healing of the tuberosities. Acta Orthop Belg 2007;73:179-87. 37.

27. Voigt C, Lill H Primary hemiarthroplasty in proximal humerus fractures [in German]. Orthopade 2007;36:1002-12. 38. 
28. Fialka C, Stampfl P, Arbe S, Reuter P, Oberleitner G, Vecsei V.Primary hemiarthroplasty in four-part fractures of the proximal humerus: randomized trial of two different implant systems. J Shoulder Elbow Surg 2008;17:210-5.

29. Nicolosi M, Gambaretti R, Broffoni L. Treatment of fractures of the humeral head by cemented and cementless hemiarthroplasty. Our experience. Chir Organi Mov 2005;90:171-7. 40.

30. Loebenberg MI, Jones DA, Zuckerman JD. The effect of greater tuberosity placement on active range of motion after hemiarthroplasty for acute fracturesof the proximal humerus. Bull Hosp Jt Dis 2005; 62: 90-3.

31. Taller S, Krivohlavek M, Lukas R, Sram J, Kral M. Hemiarthroplasty for management of proximal humeral fracture [in Czech].Acta Chir Orthop Traumatol Cech 2007;74:262-7.

32. Fallatah S, Dervin GF, Brunet JA, Conway AF, Hrushowy H. Functional outcome after proximal humeral fractures treated with hemiarthroplasty. Can J Surg 2008;51:361-5.

33. Besch L, Daniels-Wredenhagen M, Mueller M, Varoga D,Hilgert RE, Seekam A. Hemiarthroplasty of the shoulder after four-partfracture of the humeral head: a long- term analysis of 34 cases. J Trauma 2009;66:211-4.

34. Wretenberg P, Ekelund A. Acute hemiarthroplasty after proximal humerus fracture in old patients. A retrospective evaluation of 18 patients followed for 2-7 years.Acta Orthop Scand 1997;68:121-3.

35. Boileau P, Caligaris-Cordero B, Payeur F, Tinsi L, Argenson C. Prognostic factors during rehabilitation after shoulder prostheses for fracture [in French] Rev Chir Orthop Reparatrice Appar Mot 1999;85:106-16.
36. Moeckel BH, Dines DM, Warren RF, Altchek DW. Modular hemiarthroplasty for fractures of the proximal part of the humerus. J Bone Joint Surg Am 1992; 74:884-9.

37. Kollig E, Kutscha-Lissberg F, Roetman B, Mielke E, Muhr G, Hahn MP. Primary hemiarthroplasty after complex fracture of the humeral head-functional late results [in German]. Zentralbl Chi 2003;128: 125-30.

38. Grassi FA, Tajana MS. Partial prosthetic replacement of the shoulder in fractures and fracture-dislocations of the proximal humerus. Chir Organi Mov2005;90:17990. 